\title{
DE LA INVISIBILIDAD AL PROTAGONISMO. La mujer como objeto de discurso en el NO-DO
}

\author{
Matilde PEINADO RODRÍGUEZ \\ Universidad de Jaén \\ mpeinado@ujaen.es
} \begin{abstract}
NO-DO
Resumen: El artículo que presentamos toma como herramienta documental los noticiarios y documentales generados por el NO-DO (1942-1975) para analizar, desde la imagen de la mujer que nos transmiten, las pervivencias ideológicas con las que aún convivimos. La reciente apertura pública de parte de sus contenidos está incrementando las investigaciones en torno al mismo, constituyendo una fuente de primer orden para conocer la historia de la política cultural del régimen franquista y de su propaganda cinematográfica, en una España donde el cine y el NODO se presentaban como las únicas oportunidades al ocio para la mayor parte de la población femenina española. Nos proponemos de-construir el discurso narrativo que proyecta (visual, verbal, etc), como una interpretación subjetiva de la realidad que debe ser analizarla y contrastada con otras fuentes y reflexionar, en definitiva, sobre las trayectorias vitales del colectivo femenino para repensar a las mujeres como sujetos de su propia historia.
\end{abstract}

FROM INVISIBILITY TO PROTAGONISM. The woman as an object of speech in the

Abstract: The paper we present takes as a documentary tool newsreel and documentaries generated by the NO-DO (1942-1975) to analyze, from the image of women transmitted, the ideological survival with which we still live. The recent opening of the public part of its contents is increasing investigations around the same, constituting a source of first-rate to get to know the history of the cultural policy of the Franco and its cinematic image, one Spain where the film and the no-do were presented as unique opportunities to leisure for most of the female population of Spain. We intend to de-build the narrative that project (visual, oral...), as a subjective interpretation of reality that must analyze it and contrasted with other sources and reflect, in short, on the vital trajectories of the collective women to rethink the women as subjects of their own history.

Palabras clave: Franquismo. Modelo de Feminidad. NO-DO. Cátedras Ambulantes. Deconstrucción. Visibilidad

Franco's Dictatorship. Model of Femininity. No-Do. Itinerant Chairs. Deconstruction. Visibility 


\section{Fundamentación}

Investigar la influencia de la ideología y la cultura del siglo XX y su proyección social en la actualidad de nuestro país, desde la perspectiva de género, nos ofrece nuevas herramientas de reflexión para entender el difícil camino que presenta hoy la consecución real de la igualdad. El trabajo que presentamos se adscribe a una línea de investigación que contempla la pluralidad de los caminos recorridos y protagonizados no por la mujer, sino por las mujeres, como resultado de un análisis que contempla la yuxtaposición de las categorías género y clase social. La dictadura franquista (1939-1975) impuso, a través de su férreo control político e ideológico, un modelo de mujer, un unívoco concepto de feminidad, cuyos patrones fueron "cristiana piadosa, madre ejemplar, orgullo de España" (Peinado, 2012: 17). En este trabajo analizamos como dichos patrones fueron reinterpretados en forma de jerarquización, sometimiento y exclusión del colectivo femenino y de qué forma la maquinaria nacionalcatólica fundamentó en dicho sometimiento una de las claves de su pervivencia ideológica.

La formación y educación femenina, a la que con tanto celo se entregaron las chicas de la Sección Femenina ${ }^{1}$, debía ir encaminada a la plena identificación con un modelo cultural propio, específico para su género, dotado de unas particulares virtudes que constituyen la esencia de la "mujer de su casa" de "una mujer decente", es decir, todos aquellos requisitos disciplinarios que se consideraban indispensables para una buena crianza de "las mozas".

Pilar Ballarín (2001) afirma que la tradición educativa de las niñas españolas de la primera contemporaneidad hacía hincapié en los valores tradicionales y católicos así como en las herramientas útiles para el sostenimiento del hogar y de la familia. La ley de Educación Primaria de $1945^{2}$ definía una escuela segregada donde el currículum femenino debía hacer de las niñas unas perfectas amas de casa, esposas fieles al marido, madres amantísimas de sus hijas, castas y pudorosas, que deleguen confiadamente la gestión social y política a los hombres mientras cultivan los valores propios de la feminidad: como afirmar Pilar Ballarín (2001: 114), este sistema educativo retomó la prolongación de las pautas culturales y mentales fundamentadas en el constructo sexo/género, contribuyendo a la segregación social de las mujeres españolas: mujeres sumisas, dulces, silenciosas, abnegadas, obedientes y subordinadas, con un sentido de la belleza que reinaría en el interior de los hogares:

"[...] cuando una cátedra de la Sección Femenina llega a un pueblo hay revuelo de mocerío en las calles y aire de fiesta en los lugares tradicionales. La pieza fundamental de las enseñanzas para la mujer la constituye el hogar" ${ }^{.}$

Desde la última década del siglo XX, un nutrido grupo de historiadores contemporáneos han acometido el estudio del fenómeno cinematográfico desde una perspectiva sociológica e histórica, siendo Marc Ferro el maestro en la utilización del cine como línea historiográfica y fuente histórica (Caparrós Llera, 2008). No se trata de hacer, como exponen Paz y Coronado (2005: 133) un discurso histórico a través de las imágenes, sino de analizar la ideología latente en las mismas.

1 Organización de mujeres fundada por Pilar Primo de Rivera en 1934 como una sección de la Falange Española y de las Jons. Por decreto de diciembre de 1939 se les encomendó la formación política de las mujeres del Movimiento y al quedar a ella adscirto el Servicio Social obligatorio de la mujer así como determinadas asignaturas presentes en los diferentes planes de estudios del franquismo.

2 El texto de la Ley de Educación Primaria de 17 de julio de 1945 (BOE, 18 de julio de 1945), elaborado por José Ibáñez Martín, primer ministro de Educación, incorporaba los valores de tradicionalismo, catolicismo y falangismo. (opus cit Huguet, 201: 11).

3Afirmación presente en el documental de Cátedras Ambulantes (1970) http: //www.rtve.es/alacarta/videos/ revista-imagenes/ensenanza-alegria-seccion-femenina-rutas-espana/2856036/ 


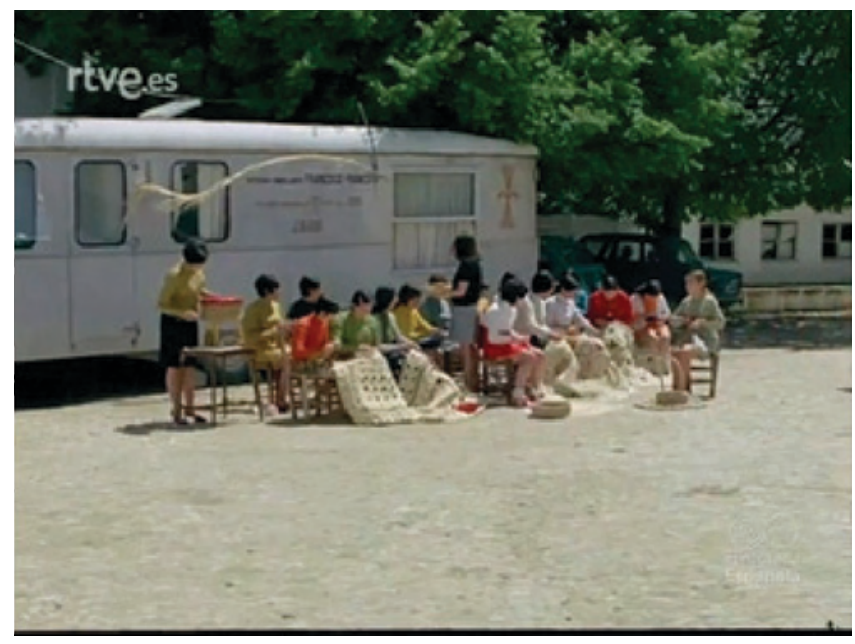

Imagen 1. Talleres de artesanía organizados por las Cátedras Ambulantes en Cárchel (Jaén) (1970). Cátedras Ambulantes (1970) http: //www.rtve.es/alacarta/videos/revista-imagenes/ensenanza-alegria-seccion-femenina-rutas-espana/2856036/

Por otra parte, y en línea con nuestro análisis desde la perspectiva de género, exceptuando los estudios culturales, como nos muestra Rosón (2016: 7), no existe un desarrollo analítico en profundidad sobre las identidades de género y sus interrelaciones con el material visual durante el primer franquismo, porque es fundamental reflexionar en torno a las pervivencias del patriarcado en la sociedad actual, a través de las mujeres que vivieron en el franquismo y educaron en este contexto a sus hijos y, fundamentalmente, a sus hijas, abuelas y madres de las nuevas generaciones.

\section{El NO-DO como herramienta analítica}

El NO-DO, (Noticiarios y Documentales), se creó por acuerdo de la Vicesecretaría de Educación Popular del 29 de septiembre 1942 y por resolución, de la misma, del 17 de diciembre del mismo año, (B.O.E. 22-12-42), como un servicio de difusión de noticiarios y reportajes, filmados en España y en el extranjero, "con el fin de mantener, con impulso propio y directriz adecuada, la información cinematográfica nacional”. Se le atribuyó la exclusiva de la producción de noticiarios, y se decretó la obligatoriedad de su exhibición en todos los cines; su proyección comenzó el primer lunes de 1943, y así se mantuvo durante los treinta y dos años siguientes, en todo el Territorio Nacional, Posesiones y Colonias. La proyección del mismo deja de ser obligatoria en septiembre de 1975.

Su producción, como expone Matud Juristo (2008) ha sido muy poco estudiada hasta el momento, si bien la reciente apertura pública de parte de sus contenidos ampliará, sin duda, las investigaciones en torno al mismo, pues constituyen una fuente de primer orden para conocer la historia de la política cultural del régimen franquista y de su propaganda cinematográfica, en una España donde el cine y el NO-DO, como afirma Ramos Lozano (2011: 33) se presentaban como las únicas oportunidades al ocio para la mayor parte de la población española, de los que las mujeres constituían sus más asiduas espectadoras.

En este marco de adoctrinamiento, propaganda y afianzamiento de los principios del Régimen a través de la elaboración y difusión de reportajes del NO-DO, se inserta un rico material cuya importancia como patrimonio cultural, como resalta Fibla Gutiérrez (2015). Trabajar con el NO-DO convierte el análisis crítico en una herramienta imprescindible para comparar la realidad mostrada y vivida de un recurso que nació como propaganda del ré- 
gimen ${ }^{4}$ y cuya razón de ser, además del contenido que nos presenta, es en sí misma una llamada a la reflexión, a la duda, a la revisión ideológica y metodológica, una lectura entre líneas imprescindible: de-construir el discurso narrativo que proyecta (visual, verbal, etc), como una interpretación subjetiva de la realidad que debe ser analizarla y contrastada con otras fuentes (documentales, archivísticas, periodísticas, orales, etc.) para entender las pervivencias de su discurso en la contemporaneidad.

Desde su nacimiento fue el único medio que realizó la crónica audiovisual del primer franquismo, gozando en exclusiva de los derechos de filmación de aquellos eventos ocurridos en el territorio nacional que contribuyeran, en esencia, a consolidar el Nuevo Estado sobreponiendo, como expone Rodríguez Mateos (2005: 179) la dimensión propagandística del relato, de forma ampulosa y hueca, y con una evidente intención ideológica, a la dimensión informativa.

Partiendo de esta línea argumental, nos proponemos en las siguientes líneas analizar, por una parte, como expusiera Derrida (opus cit Tranche y Sánchez-Biosca, 1995) el archivo reprimido, entendiendo bajo este concepto no sólo aquello que no se filmó, que nunca salió a la luz, denominado también por Rosón (2016: 6) como reverso del archivo, el silencio, lo no dicho, lo que aparentemente no permanece...; sino aquellas otras realidades que conviven en la escena, en segundos planos y planos generales, pues es precisamente en dichas otredades, en esa otra sociedad oficiosa, no institucional, no relevante, donde la presencia de las mujeres emerge para reescribir su propia historia, a pesar de hacerlo desde la fidelidad al papel pautado por el Régimen, al modelo de feminidad establecido: desde la abnegación, la subsidiariedad, la complementariedad, que la relega irremediablemente a la abstracción y la objetivación de la masa: aquella que aplaude enfervorizada al paso del Caudillo, que llena las plazas y da muestra del apoyo social al Régimen, pero que nunca es protagonista de los hechos relevantes, protagonizados e historiados en clave masculina.

\section{La mujer en los noticiarios del NO-DO: protagonistas y espectadoras}

Analizar el NO-DO desde la perspectiva de género, en sintonía con la línea de investigación a la que se adscribe este trabajo, es ante todo entender la historia de las mujeres en tanto que multilinealidad de los procesos, cruzando las categorías género y clase social, donde las mujeres, en su doble faceta de protagonistas y espectadoras, transitan en el universo circular de la feminidad, en tanto que modelo unívoco de mujer diseñado e impuesto por la maquinaria franquista.

Los ideólogos de dichos noticiarios, no sólo los diseñaron como herramienta de propaganda y exaltación del Régimen, algo por otra parte obvio, sino que concibieron a su público como un destinatario plano, más visceral que racional (Rodríguez Mateos, 2005: 198), sin capacidad de análisis, que se convencía y emocionaba al ritmo marcado por la voz monocorde y grandilocuente del narrador. A todas las mujeres, además, se les conferían otros atributos específicos de "su sexo" como su superficialidad y frivolidad, que las hacía destinatarias idóneas de noticias ajenas a la realidad socioeconómica y política imperante, blandas, diseñadas desde postulados estéticos (aspecto físico, muebles, decoración, modo...), propias un "estilo femenino" que implicaba no una forma de ser sino fundamentalmente de estar en el mundo, una cultura femenina visual.

Como aprecia Rosón (2016: 63) el noticiario se pensó como una "revista cinematográfica" interesado en implicar al público femenino como potencial espectador "cautivo", a las que se les mostraba, en una suerte de estructura piramidal, a Carmen Polo, en la cúspide,

4 Fibla Gutiérrez (2015: 295) lo define como una pieza fundamental para entender la relación entrepoder e imaginario en la sociedad española,pues ofrecerá a los españoles una imagen oficialista, manipulada y en ocasiones delirante de la realidad socio-política del mundo. 


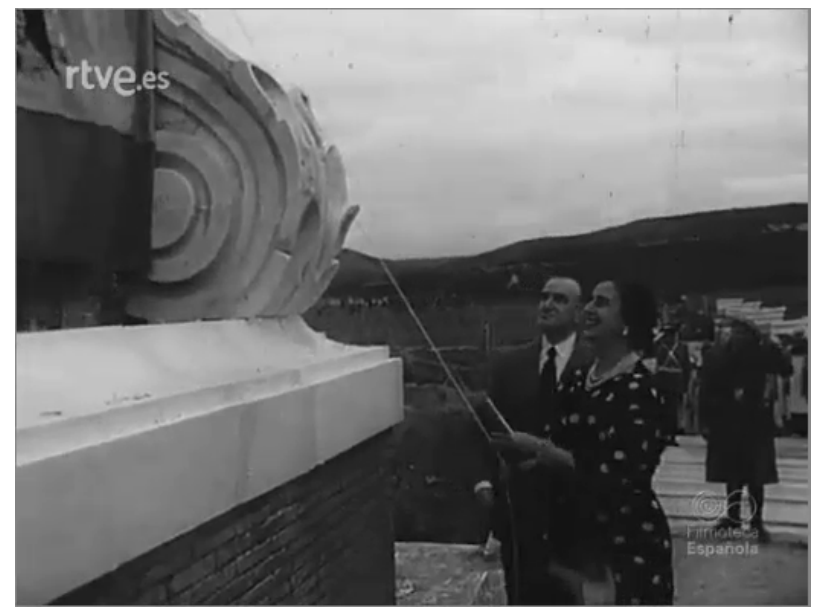

\section{Imagen 2.Carmen Polo inaugura el Pantano de Guadalén (Jaén) (1953). Noticiario 540A (http: //www.rtve.es/filmoteca/no-do/not-540/1487603/).}

con ese porte de mujer matrona, avejentada, portadora de vestidos y trajes sin formas, con moño bajo, sin tintes, parapetada en su papel de consorte ${ }^{5}$, sin más habilidades que la de participar en los actos religiosos, correr cortinillas o cortar cintas en destacadas inauguraciones, mujer de su casa, amantísima madre de familia.

Por debajo de ella no había, en el caso del colectivo femenino, una clase femenina dirigente, pues las altas jerarquías militares y civiles eran exclusivamente masculinas ${ }^{6}$, sólo una masa uniforme de mujeres de clase baja con las que se identifican las espectadoras, en su mayoría, como expone dicha autora (2016: 33) expuestas aún más a una influencia que no complementaban instrumentos como la prensa escrita o la radio. Estas mujeres anónimas participan en los actos multitudinarios, a menudo con sus vástagos en brazos, o abandonan excepcionalmente su papel subsidiario para representar otros igualmente secundarios, pero eminentemente o exclusivamente femeninos: son los casos de las mujeres y niñas que lanzan pétalos al paso de la comitiva o del mismo Caudillo, que amenizan los actos con sus bailes folclóricos, que adornan con los trajes típicos de cada localidad las carrozas de los desfiles o que vitorean a las autoridades civiles o militares desde los balcones. La persuasión se completa, como analiza Ramos Lozano (2011: 29), a través de la fascinación que producen la ceremonia y el rito que orbita en torno a estos actos, y que se repite con el mismo formato una y otra vez ante la admiración de los espectadores.

No están, sin embargo, en las inauguraciones de los pantanos ${ }^{7}$, centros de formación o granjas escuelas, en las visitas guiadas a las fábricas ${ }^{8}$, ni tampoco cuando Franco entrega los

5 Como expone Coronado (2008: 21) el régimen, a través de los medios de comunicación difundió el mito de la donna-madre, que contraponía al de la donna crisi: mujer urbana, andrógina, delgada, histérica, decadente y estéril frente a la mujer-madre: ancha de caderas, rolliza, mofletes colorados, patriótica, fuerte, tranquila y prolífica.

6 Si bien las altas jerarquías de la Sección Femenina participavan en actos no organizados por ellas, hay indicios como expone Ramos Lozano (2011: 73) para aventurar que la invisibilización y ocultación de estas presencias fue una práctica común, por tanto, podemos afirmar que fueron igualmente invisibilizadas con la excepción de los actos organizados y dirigidos a mujeres con una clara intencionalidad modélica y adoctrinadora.

7Inauguración de un pantano en el marco de su visita a Andalucia (Noticiario 441bhttp: //www.rtve.es/filmoteca/ no-do/not-441/1487436/)

8 Hemos encontrado en este ámbito una excepción, el noticiario dedicado a la inauguración de una fábrica exclusivamente de operarias femeninas. En Linares visitan dos fábricas, la de Santana, todo hombres y, posteriormente, visitan la oleometalgráfica del sur, donde se indica que un $70 \%$ de las trabajadoras son mujeres, un hecho 


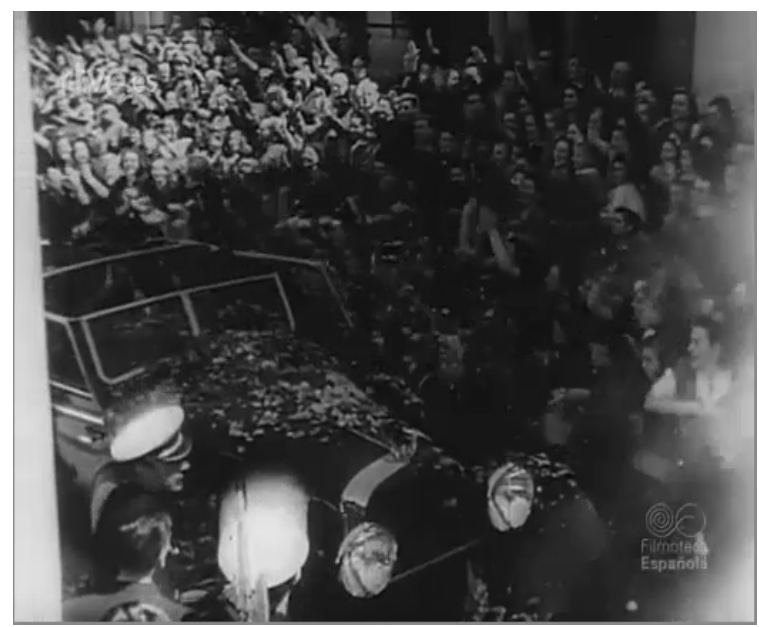

Imagen 3: mujeres tiran flores al paso de la comitiva del Caudillo (1943). Noticiario 21b (http: //www.rtve.es/filmoteca/no-do/not-21/1487668/)

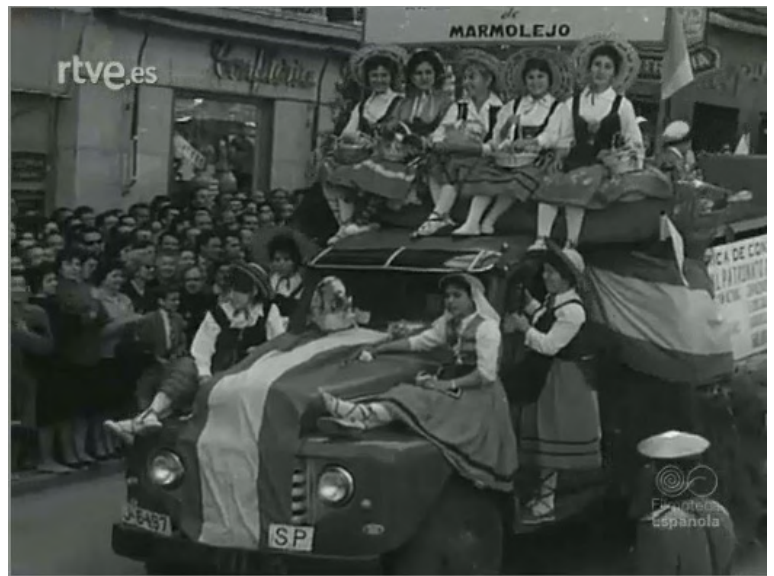

Imagen 4. Mujeres “adornan” las carrozas del desfile del Plan Jaén (1958).

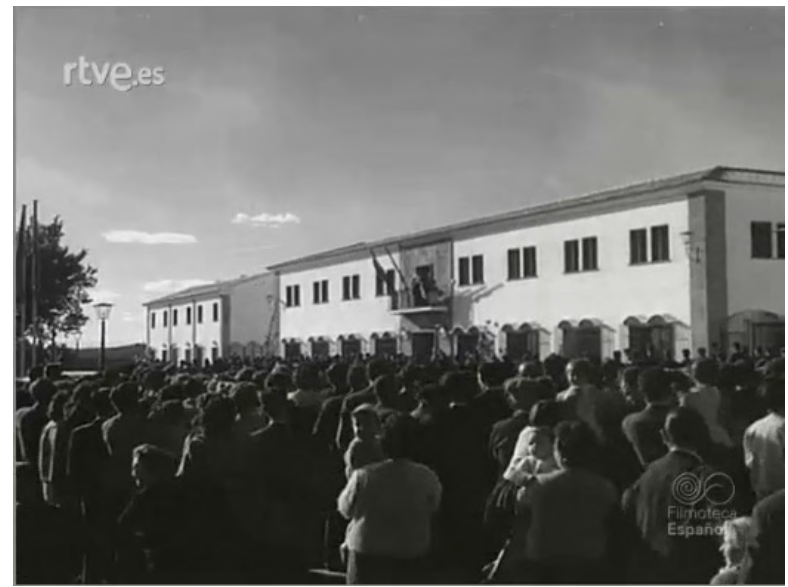

Imagen 5. Inauguración de una granja-escuela en Marmolejo (Jaén) (1958). Noticiario 956B http: //www.rtve.es/filmoteca/no-do/not-956/1470430/ 


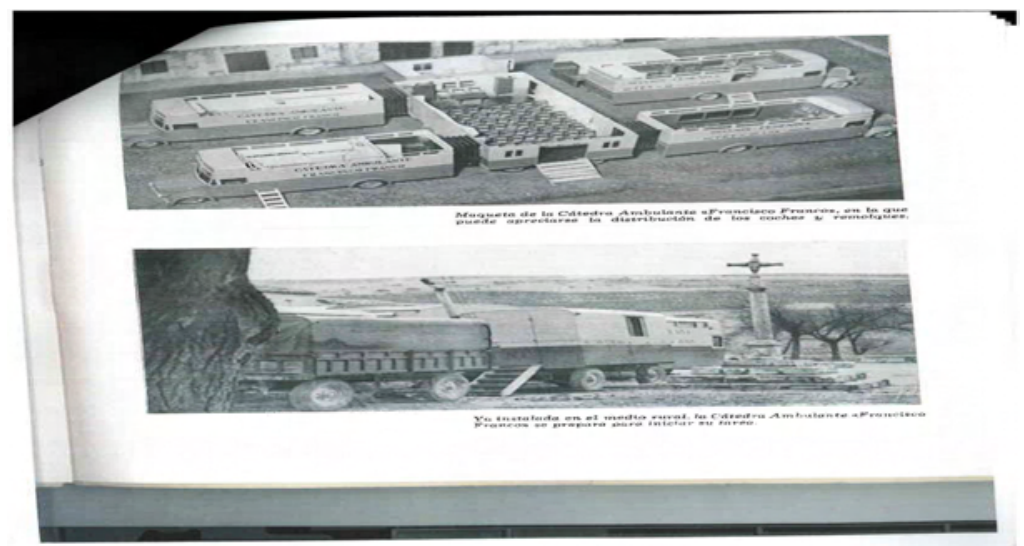

Imagen 6. La cátedra Ambulante Francisco Franco

títulos y llaves de casas a los nuevos colonos, en barriadas sociales, donde es el patriarca, en exclusiva, el que recibe, en representación de la familia, la titularidad de la propiedad ante las cámaras.

Así, es interesante rescatar, en este punto, el noticiario que documenta la inauguración de una granja-escuela en la provincia de Jaén donde la cámara registra, sin intención, como las mujeres, con sus hijos a cuestas, atisban, desde fuera de la fábrica, a una distancia prudencial, el evento que está sucediendo dentro, en el que participan sus maridos o hijos, para el que evidentemente, no tienen permitido el acceso.

\section{Las Cátedras Ambulantes: cómo visibilizar un modelo de feminidad}

Las Cátedras Ambulantes", denominadas también "las escuelas viajeras", fueron una agrupación móvil (cuatro camiones con sus respectivos remolques) de la Falange de la Sección Femenina que se definía a sí misma como "un medio nuevo, atractivo y eficaz de llevar a los pueblos y aldeas la atención, la cultura, los adelantos y conocimientos más prácticos para el mejor desarrollo de su asistencia material y moral (Maggi, 2000). Comenzaron su labor en los años 40 y tuvieron continuidad cronológica hasta 1977, llegando a funcionar 72 Cátedras Ambulantes por todo el país con 360 profesoras (Pérez Moreno, 2013: 17).

Como exponen Tranche y Sánchez-Biosca (2006: 219) esta organización dedicará su actividad a formar a las mujeres españolas en tres áreas: religiosa, nacionalista y de preparación del hogar, una triada que se contemplaba siempre bajo un mismo prisma "servir", las mujeres sirviendo a sus maridos, a sus familias, y las chicas de la Sección Femenina sirviendo a la patria para "elevar el nivel social, económico, cultural y espiritual, que denominaban

tan inverosímil que el propio narrador se refiere a ello, especificando el porcentaje que trabaja en las mismas. 9 "Enseñanza y alegría: la Sección Femenina por las rutas de España" (1960): http: //www.rtve.es/alacarta/ videos/revista-imagenes/ensenanza-alegria-seccion-femenina-rutas-espana/2856036/

"Tembleque en el NO-DO." (1970): https: //www.youtube.com/watch?v=qn0DzieusWs (1970).Enseñanza y alegría de la Sección Femenina (1960).

El 26 de mayo de 1975, el noticiario 1689B del NO-DO, http: //www.rtve.es/filmoteca/no-do/not-1689/1487628/, con motivo de la conmemoración del Año Internacional de la Mujer, rinde un homenaje a la Sección Femenina que "...desde hace casi cuarenta años, lleva realizando una labor no por callada, menos eficaz, para integrar a la mujer española en un ámbito social más acorde con la evolución de la vida...” “...Estas imágenes muestran cómo se ha preocupado en todo momento por la promoción de la mujer, especialmente los medios rurales, quizá los más atrasados y deprimidos." Como defienden Tranche y Sánchez- Biosca (2006), en dicho noticiario se obviará toda referencia a la necesaria emancipación de la mujer, asociándola de nuevo con tareas secundarias o vinculadas a su condición maternal (deportes femeninos, guarderías, etc). 


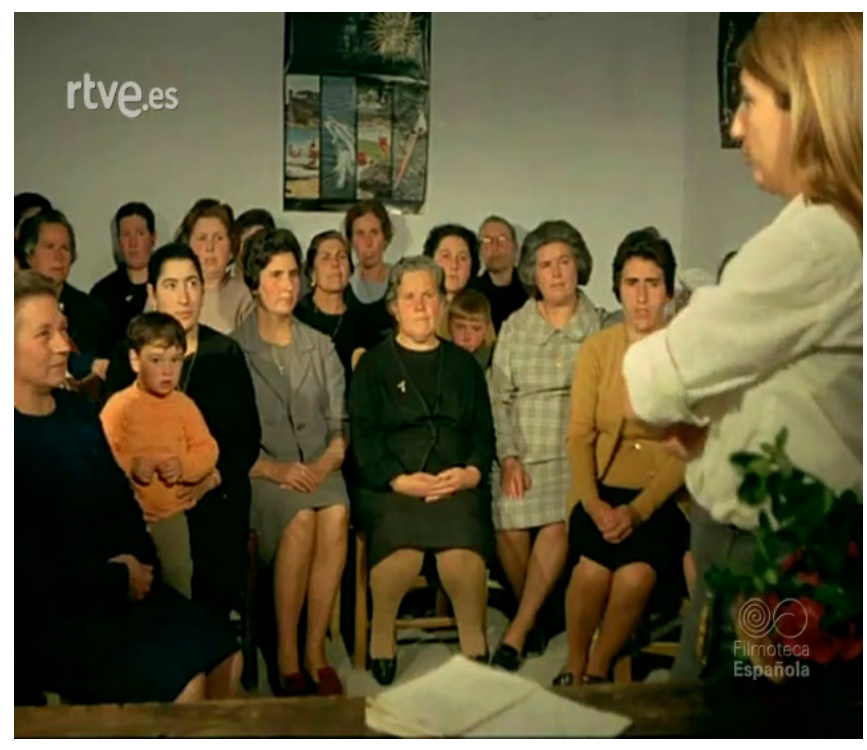

Imagen 7. Una instructora de la Sección Femenina instruye a las vecinas de Cárchel (Jaén) sobre el parto y puerperio (1970). https: //www.youtube.com/watch?v=qn0DzieusWs (1970). Enseñanza y alegría de la Sección Femenina (1960).

como "regeneración social" de la ciudadanía de enclaves geográficos-pueblos y aldeas de menos de 5000 habitantes-deprimidos y con variadas carencias. El adoctrinamiento político era clave en esta regeneración, pues consideraban que:

"[...] la formación política sirve para darles un conocimiento de las bases doctrinales del Estado, de su legislación social, de cómo, en su propia aldea, sin desarraigarse y en sus propios quehaceres cotidianos, pueden y tienen que estar vinculados a la Patria."

Como refleja Pérez Moreno (2013: 2) las Cátedras Ambulantes de la Sección Femenina, en virtud de su carácter educativo no formal, de sus destinatarios geográficos y personales y de su genérica misión son relevantes para entender la educación social en nuestro país, y fundamentalmente, el modelo oficial de feminidad que con tanto empeño trataban de inculcar sus instructoras.

Franco encargo a la Sección Femenina, a través de su fundadora y delegada nacional vitalicia, Pilar Primo de Rivera, la educación y adoctrinamiento de la mujer española, entendiendo, como venimos argumentando, que ellas, en tanto que fundamento y piedra angular de la familia patriarcal (Peinado, 2012: 30) eran el instrumento idóneo de transmisión de los valores tradicionales, la regeneración desde la tradición, entendiendo dicha tradición como la modernidad del momento, formar "modernas mujeres a la antigua" "[...] llegar a las mujeres de las zonas rurales y así incorporarlas al momento actual de la vida española".

Sin embargo, como reflexiona Morcillo (2012: 44) aunque eran portadoras de algunos de los avances del despegue económico, ello se integraba en el mantenimiento y desempeño de "sus labores" de acuerdo con la mentalidad doméstica y hogareña dentro y fuera del hogar:

“[...] La mujer necesita manejar hoy por igual la escoba y el destornillador, no sólo porque los cacharros domésticos tienen cada vez más palancas y enchufes sino porque las damas se motorizan; por ello la Sección Femenina ha preparado unos cursillos de mecánica." 
Con el tiempo, su labor se amplió a la totalidad de sus habitantes, como narraba la propia Delegada Nacional:

"En un principio la Cátedra se pensó dirigida exclusivamente a la mujer; el programa era ambicioso: alfabetización, lucha contra la mortalidad infantil, campañas de higiene y divulgación sanitario-social, formación para el hogar, preparación para una mejor explotación de los propios recursos. Muy pronto los hombres empezaron también a interesarse en una serie de enseñanzas tales como, por ejemplo, el curtido y aprovechamiento de pieles, las posibilidades de explotación de los animales domésticos [...]"10

Sin embargo, las mujeres, y sobre todo "las mozas"11 fueron siempre su objetivo prioritario, unas mozas a las que había que instruir para ser "buenas esposas, madres y amas de casa": "[...] enseñar a las mozas cómo se pone una mesa, cómo se hace un buen uso de los cubiertos o cómo se atiende debidamente el servicio del comedor".

Estas enseñanzas debían siempre observarse desde el recato y pudor de su edad y condición, por lo que las clases no sólo se segregaban en función del sexo sino también de la edad, evitando siempre la formación conjunta de solteras y casadas, pues éstas últimas podían anticipar a las tiernas adolescentes experiencias venideras para las que aún no estaban convenientemente formadas.

Por ello, las disciplinas en las que se centraron todos los esfuerzos fueron, fundamentalmente, aquellas vinculadas desde siempre al universo femenino: la formación religiosa en colaboración con los párrocos; la sanidad con informaciones referentes a la higiene y al cuidado de los niños/as, especialmente de los bebés, junto con la campaña de vacunación y reconocimiento médico, a través de talleres denominados "madres ejemplares"; enseñanzas sobre industrias caseras que permitían aumentar los ingresos familiares; la formación político-social sobre la doctrina falangista; la puesta en práctica de un método que erradicase el analfabetismo, la enseñanza de la educación física para las mujeres ${ }^{12}$ ("[...] la gimnasia rítmica, un aspecto de la cultura física desarrolla el gesto grácil y femenino dentro de tradicionales ejercicios) y la enseñanza y recopilación del folklore nacional, con recogida de músicas y bailes tradicionales.

\section{Apuntando algunas conclusiones}

El cine, como Patrimonio Cultural, se ha convertido en una fuente para el conocimiento y recuerdo de la memoria del siglo XX. El NO-DO, es una herramienta de análisis con enormes potencialidades para reflexionar, a través de sus imágenes y comentarios, en torno a la evolución espacio-temporal de nuestro país y su repercusión en el ámbito antropológico, histórico, sociológico e ideológico desde la perspectiva de género, descendiendo al análisis del modelo unívoco de mujer que el aparato franquista articulo y transmitió a través del mismo, un modelo cuyos principios ideológicos fueron determinantes en la consolidación y perpetuación del régimen.

10 Pilar Primo de Rivera (opus cit Gómez Fernández, 2010: 93).

11 Las actividades podían ocupar literalmente toda la jornada de lunes a sábado según el horario recomendado por la organización Femenina: de 9 a 13: 15 horas por las mañanas para las mozas, de 15 a 19: 30 por las tardes para mozas, madres y juventudes y de 21 a 22: 30 horas para mozas y toda la ciudadanía en general.

12 Como analiza Ramos Lozano (2011: 97) en el caso de las mujeres, un cuerpo fuerte permitía traer al mundo hijos sanos a los que transmitir el ideario falangista: moldear el cuerpo social para que fuera disciplinado y a la vez perpetuarlo, estableciendo una relación con el cuerpo, de lo físico, con las cualidades morales no sólo del individuo sino de la comunidad a la que pertenece, y, por tanto, la educación física femenina tenía menos que ver con el entrenamiento que con la idea de disciplina, control y salud de las futuras madres. 
Conocer el modelo de feminidad diseñado por y para las mujeres de la España franquista es conocer la historia desde la inclusión, desde la igualdad, desde el reconocimiento de las trayectorias vitales del colectivo femenino, reconocer a la otra mitad como sujetos de una historia que hasta ahora otros han escrito y pensado para ellas: llego el momento de repensar a las mujeres como sujetos de su propia historia, una historia articulada tanto desde los escenarios audiovisuales visibles como desde los archivos reprimidos, los silencios, las exclusiones: la invisibilidad.

La reflexión conceptual e ideológica del patriarcado y sus pervivencias en el siglo XXI continúa orbitando en las investigaciones que tratan de dilucidar las causas del fracaso efectivo, real, cotidiano, de los avances legislativos en material de igualdad y no puede ser de otra forma en una sociedad, como la española, que continúa viviendo y padeciendo sus envites y reminiscencias, cuyas repercusiones trascienden, y de qué manera, un modo de ser, estar y entender la vida de las mujeres de este país y no sólo de las generaciones que se formaron en aquellos años (Peinado Rodríguez, 2018).

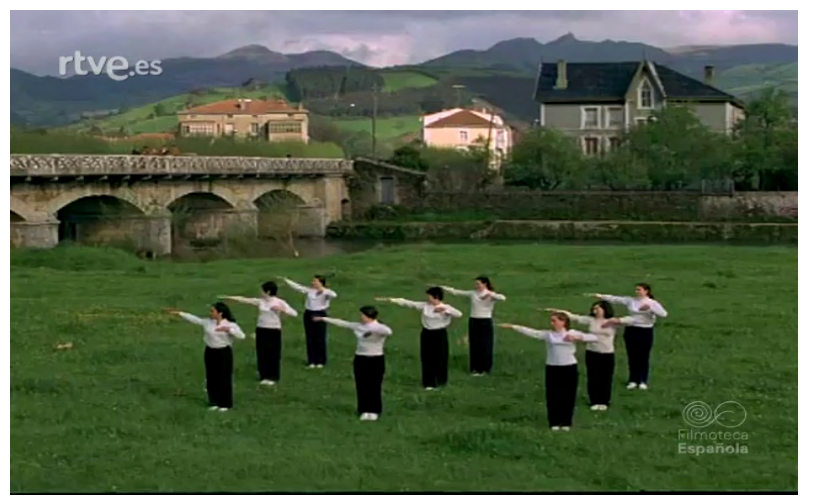

Imagen 8. Las instructoras de la Sección Femenina imparten clases de Educación Física. "Enseñanza y alegría: la Sección Femenina por las rutas de España” (1960): http: //www.rtve.es/ alacarta/videos/revista-imagenes/ensenanza-alegria-seccion-femenina-rutas-espana/2856036/.

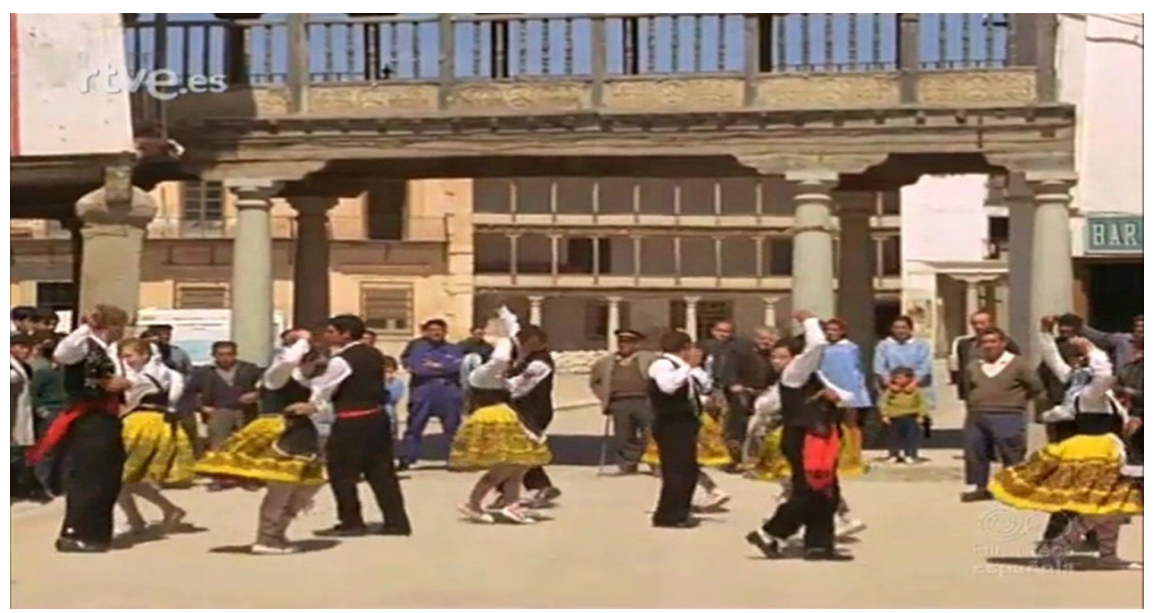

Imagen 9.Recuperación del folklore autóctono gracias a la labor de las Cátedras Ambulantes. https: //www.youtube.com/watch?v=qn0DzieusWs (1970). Enseñanza y alegría de la Sección Femenina (1960). 
El ejercicio de una ciudadanía activa y comprometida con la mejora de las condiciones de vida, exige necesariamente la articulación de un universo social en clave de igualdad, deconstruyendo las pervivencias ideológicas que una sociedad como la española aún mantiene en torno al universo femenino que amenazan con perpetuarse como valores universales desde la adscripción "natural" al colectivo femenino.

\section{Bibliografía}

BALLARÍN DOMINGO, Pilar (2001). La educación de las mujeres en la España Contemporánea (siglos XIX-XX). Madrid: Síntesis Educación.

BELLO CUEVA, José. Antonio (2000). «El NO-DO, hoy». Cuadernos de documentación multimedia, 9.

CAPARRÓS LLERA, Josep M $\mathrm{M}^{\mathrm{a}}$ (2008). «¿Es posible explicar la Historia desde el cine? » Consultado el 11-9-2016, recuperado de http: //www.cinehistoria.com/archives/104.

FIBLA GUTIÉRREZ, Enrique (2015). «NO-DO: Archivo y secuestro de la imaginación». Icono 14, (13), 294-313.

GÓMEZ FERNÁNDEz, Ana Belén (2010). «La llegada de las Cátedras Ambulantes de la Sección Femenina a Sierra Mágina». Sumuntán, 28, 89-104.

LEÓN, Maggi de (2000). Las voces del silencio. Memoria de una Instructora de juventudes de la Sección Femenina. Madrid: Edición de Autor.

MARÍN MUÑOZ, Antonio (2007). La reconstrucción de la provincia de Jaén bajo el franquismo (1939-1957). Jaén: Gráficas Francisco del Moral.

MATUD JURISTO, Álvaro (2008). «La incorporación del cine documental al proyecto del NO-DO». Historia y Comunicación Social, 13, 105-118.

MORCILLO GÓMEZ, Aurora (2012). «Españolas con, contra, bajo, el franquismo». Desacuerdos, 7, 42-63.

PAZ, Ma Antonia. y CORONADO, Carlota (2005). Mujer y formación profesional durante el franquismo. No-do, 1943-1975. Consultado el 12-09-2016, recuperado en https: //dialnet.unirioja.es/descarga/articulo/2564574.pdf

PEINADO RODRÍGUEZ, Matilde (2010). Iglesia y Falange: encuentros y desencuentros en el ámbito de la Educación Femenina, en Encuadramiento femenino, socialización y cultura en el franquismo. Málaga: Diputación.

PEINADO RODRÍGUEZ, Matilde (2012). Enseñando a señoritas y sirvientas. Educación femenina y clasismo en el franquismo. Madrid: Catarata.

PEINADO RODRÍGUEZ, Matilde y ANTA FÉLEZ, José Luis (2013). «Educar para el matrimonio en femenino: modelos y prácticas en la literatura de posguerra». Athenea Digital, no 13(2), 35-46.

PEINADO RODRÍGUEZ, Matilde (2016). «El NO-DO como recurso didáctico en Geografía: un análisis de los sectores productivos desde el Plan Jaén(1953)» en Nativos Digitales y Geografía del siglo XXI: Educación Geográfica y estilos de aprendizaje. Sevilla: Universidad de Sevilla y grupo de Didáctica de la Geografía.

PEINADO RODRÍGUEZ, Matilde (2018). La estigmatización de la soltería femenina en la España Franquista (en prensa).

PÉREZ MORENO, Heliodoro (2004). Una escuela viajera: La Cátedra Ambulante de la SF de Huelva (1956-1977). Huelva: Servicio de Publicaciones de la Diputación de Huelva.

PÉREZ MORENO, Heliodoro (2013). «Educación y asistencia social en una escuela errante durante el franquismo en España». Revista de Educación Social, 17, 1-16.

RAMOS LOZANO, Pilar (2011). Comunicación y estrategias organizativas de la Sección Femenina de la Falange. Representaciones: NO-DO, 1943-1953. Málaga: Atenea.

RODRÍGUEZ MARTÍNEZ, Saturnino (1999). NO-DO. Catecismo social de una época. Madrid: Editorial Complutense.

RODRÍGUEZ MATEOS, Araceli (2005). «La memoria oficial de la Guerra Civil en NO-DO» (19431959) Revista Historia y Comunicación Social, 10, 179-200.

RODRÍGUEZ MATEOS, Araceli (2008). Un franquismo de cine. La imagen política del Régimen en el noticiario NO-DO. Madrid: Rialp. 
ROSÓN, María (2016). Género, memoria y cultura visual en el primer franquismo. Madrid: Cátedra.

SÁNCHEZ MARTÍNEZ, José Domingo y JÓDAR MENA, Manuel (2017). «EL No-do, fijador de miradas y forja de identidad territorial: el caso de la provincia de Jaén» en Actas del XXV Congreso de la Age, Madrid (en prensa).

SECCIÓN FEMENINA DE FET Y DE LAS JONS (1951). Cátedra Ambulante "Francisco Franco". Madrid: Altamira.

SECCIÓN FEMENINA DE FET Y DE LAS JONS (1965a). Cátedras de la Sección Femenina. Organización. Madrid, Industrias Gráficas Magerit.

SECCIÓN FEMENINA DE FET Y DE LAS JONS (1965b). Cátedras de la Sección Femenina. Programas. Madrid: Industrias Gráficas Magerit.

TRANCHE, Rafael y SANCHEZ-BIOSCA, Vicente (2006). NO-DO. El tiempo y la memoria. Madrid: Cátedra. 